\title{
Genome-Wide Association Study Meta-Analysis for Parkinson Disease Motor Subtypes
}

Isabel Alfradique-Dunham, MD,* Rami Al-Ouran, PhD, * Rainer von Coelln, MD, * Cornelis Blauwendraat, PhD, Emily Hill, MD, Lan Luo, MD, MS, Amanda Stillwell, BA, Emily Young, MD, Anita Kaw, BA, Manuela Tan, BA, Calwing Liao, BA, Dena Hernandez, PhD, Lasse Pihlstrom, MD, PhD, Donald Grosset, MD, Lisa M. Shulman, MD, Zhandong Liu, PhD, Guy A. Rouleau, MD, PhD, Mike Nalls, PhD, Andrew B. Singleton, PhD, Huw Morris, MD, Joseph Jankovic, MD, and Joshua M. Shulman, MD, PhD, on behalf of the International Parkinson's Disease Genomics Consortium

Neurol Genet 2021;7:e557. doi:10.1212/NXG.0000000000000557

\section{Abstract}

\section{Objective}

To discover genetic determinants of Parkinson disease (PD) motor subtypes, including tremor dominant (TD) and postural instability/gait difficulty (PIGD) forms.

\section{Methods}

In 3,212 PD cases of European ancestry, we performed a genome-wide association study (GWAS) examining 2 complementary outcome traits derived from the Unified Parkinson's Disease Rating Scale, including dichotomous motor subtype (TD vs PIGD) or a continuous tremor/PIGD score ratio. Logistic or linear regression models were adjusted for sex, age at onset, disease duration, and 5 ancestry principal components, followed by meta-analysis.

\section{Results}

Among 71 established PD risk variants, we detected multiple suggestive associations with PD motor subtype, including GPNMB ( $\left.r s 199351, p_{\text {subtype }}=0.01, p_{\text {ratio }}=0.03\right), S H 3 G L 2\left(r s 10756907, p_{\text {subtype }}\right.$ $\left.=0.02, p_{\text {ratio }}=0.01\right), \operatorname{HIP} 1 R\left(r s 10847864, p_{\text {subtype }}=0.02\right), R I T 2\left(r s 12456492, p_{\text {subtype }}=0.02\right)$, and FBRSL1 $\left(r s 11610045, p_{\text {subtype }}=0.02\right)$. A PD genetic risk score integrating all $71 \mathrm{PD}$ risk variants was also associated with subtype ratio $(p=0.026, B=-0.04,95 \%$ confidence interval $=-0.07-0)$. Based on top results of our GWAS, we identify a novel suggestive association at the STK32B locus $\left(\right.$ rs2301857, $\left.p_{\text {ratio }}=6.6 \times 10^{-7}\right)$, which harbors an independent risk allele for essential tremor.

\section{Conclusions}

Multiple PD risk alleles may also modify clinical manifestations to influence PD motor subtype. The discovery of a novel variant at $S T K 32 B$ suggests a possible overlap between genetic risk for essential tremor and tremor-dominant PD.
Correspondence

Dr. Shulman

Joshua.Shulman@bcm.edu

\footnotetext{
*These authors contributed equally and are co-first authors.
}

From the Department of Neurology (I.A.-D., E.H., L.L., A.S., E.Y., A.K., J.J., J.M.S.), Baylor College of Medicine, Houston, TX; Department of Pediatrics (R.A.-O., Z.L.), Baylor College of Medicine, Houston, TX; Jan and Dan Duncan Neurological Research Institute (R.A.-O., Z.L., J.M.S.), Texas Childrens Hospital, Houston, TX; Department of Neurology (R.C., L.M.S.), University of Maryland School of Medicine, Baltimore, MD; Molecular Genetics Section (C.B., D.H., M.N., A.B.S.), Laboratory of Neurogenetics, National Institute on Aging, National Institutes of Health, Bethesda, MD; Department of Clinical and Movement Neurosciences (M.T., H.M.), UCL Queen Square Institute of Neurology, University College London, London, UK; UCL Movement Disorders Centre (M.T., H.M.), UCL Queen Square Institute of Neurology, University College London, London, UK; Montreal Neurological Institute (C.L., G.A.R.), Montréal, Quebec, Canada; Department of Human Genetics (C.L., G.A.R.), McGill University, Montréal, Quebec, Canada; Department of Neurology (L.P.), Oslo University Hospital, Oslo, Norway; Department of Neurology (D.G.), Institute of Neurological Sciences, Queen Elizabeth University Hospital, Glasgow, UK; Department of Neurology and Neurosurgery (G.A.R.), McGill University, Montréal, Quebec, Canada; Data Tecnica International (M.N.), Glen Echo, MD; Parkinsons Disease Center and Movement Disorders Clinic (.J., J.M.S.), Department of Neurology, Baylor College of Medicine, Houston, TX; Department of Molecular \& Human Genetics (J.M.S.), Baylor College of Medicine, Houston, TX; and Department of Neuroscience (J.M.S.), Baylor College of Medicine, Houston, TX.

Funding information and disclosures are provided at the end of the article. Full disclosure form information provided by the authors is available with the full text of this article at Neurology.org/NG.

International Parkinson's Disease Genomics Consortium coinvestigators are listed in the appendix 2 at the end of the article. 


\section{Glossary}

BCM = Baylor College of Medicine; ET = essential tremor; GRS = genetic risk score; GWAS = genome-wide association study; IPDGC = International Parkinson's Disease Genomics Consortium; MAF = minor allele frequency; MDS-UPDRS = Movement Disorder Society revised UPDRS version; PD = Parkinson disease; PIGD = postural instability/gait difficulty; TD = tremor dominant; UPDRS = Unified Parkinson's Disease Rating Scale.

Parkinson disease (PD) is a clinically heterogeneous disorder. ${ }^{1-6}$ PD subtypes have been described based on common patterns of phenotypic features. ${ }^{1,7}$ One of the earliest and widely used subtyping classifications recognizes tremor dominant (TD) and postural instability/gait difficulty (PIGD) motor subtypes. ${ }^{8,9}$ These subtype categories have implications for disease progression, with prospective studies showing that PIGD is characterized by increased cognitive impairment and decreased response to levodopa. ${ }^{10,11}$ Although some studies have sought to identify pathologic correlates for PD motor subtypes, ${ }^{12,13}$ the mechanisms underlying these clinical and prognostic differences remain incompletely understood. ${ }^{7}$ Others have raised questions about the stability of PD motor subtypes over the disease course and their potential to be influenced by medications ${ }^{14-16}$

A strong genetic contribution to PD etiology is well established, including several rare, monogenic forms of the disease and a large number of common variant PD risk alleles identified in genome-wide association studies (GWASs).${ }^{17}$ There is mounting evidence for genetic variants as modifiers of $P D$ phenotype as well. Variants in LRRK2 or GBA modify disease motor progression (slower or faster, respectively) and also affect risk of cognitive impairment. ${ }^{18,19}$ Genetic association studies have also nominated genetic modifiers of PD progression, cognitive impairment, age at onset, and risk of insomnia, including established PD risk alleles. ${ }^{19-28}$ Of interest, LRRK2(G2019S) carriers appear to have a higher incidence of the PIGD subtype, despite early reports of asymmetrical tremor as a prominent clinical feature. ${ }^{18,29}$ A recent analysis of 10 PD risk variants from GWAS in a sample of 251 subjects (plus 559 subjects for replication) demonstrated an association of an SNCA locus polymorphism with the TD subtype. ${ }^{23}$

We performed a GWAS meta-analysis for PD motor subtype in 3,212 subjects, examining potential associations for 71 established PD risk alleles and further testing for novel modifiers of TD vs PIGD motor phenotypes.

\section{Methods}

\section{Standard Protocol Approvals, Registrations, and Patient Consents}

Subjects derived from multiple North-American and European PD research cohorts (table e-1, links.lww.com/NXG/ A373): Baylor College of Medicine (BCM), University of Maryland, Baltimore PD Genetics Study, Parkinson's Progression Markers Initiative, Parkinson's Disease Biomarkers
Program, Profiling Parkinson's disease study (Netherlands), Tracking Parkinson's study (United Kingdom), and the Oslo Parkinson's Disease study (Norway). All participants provided written informed consent for genomic studies, including permission for sharing of deidentified data between institutions, before enrollment in the respective studies. We obtained all clinical and genetic information with approval of the respective local institutional review boards.

\section{Participants}

All subjects were diagnosed with PD. The following data were required for inclusion in this study: sex, age at symptom onset, age at diagnosis, age at first evaluation, and earliest available (baseline) itemized rating using the Unified Parkinson's Disease Rating Scale (UPDRS) parts 2 and 3 or the equivalent parts of the Movement Disorder Society revised UPDRS version (MDS-UPDRS). ${ }^{30,31}$ Disease duration in years was defined as age at first evaluation minus age at symptom onset. If age of symptom onset was not available, age at diagnosis was used. The BCM cohort included subjects evaluated with either version of the UPDRS, and these subjects were therefore evaluated as separate cohorts (BCM1 and BCM2, see table e-1, links.lww.com/NXG/A373). All other cohorts exclusively used either the UPDRS or the MDS-UPDRS.

\section{Motor Subtypes}

PD motor subtypes, TD and PIGD, were determined using previously published algorithms. ${ }^{1,2}$ Subjects are classified as either TD, PIGD, or indeterminate using scale-specific cutoffs based on the ratio of tremor score to PIGD score from the UPDRS or MDS-UPDRS parts II and III. Applying these algorithms to our pooled cohort, 383 subjects with a tremor/ PIGD score ratio in the indeterminate range could not be assigned to either the TD or PIGD dichotomous trait. As a complementary approach, we therefore used the tremor/ PIGD score ratio as a continuous outcome, permitting inclusion of all subjects (including those classified as indeterminate). To accommodate subjects with PIGD score $=$ 0 in these analyses, we transformed the tremor/PIGD score ratio as follows:

$$
\log \sqrt{\frac{\text { Tremor score }+0.01}{\text { PIGD score }+0.01}}
$$

\section{Genotyping}

Genotyping data (all Illumina platform based) were obtained from International Parkinson's Disease Genomics Consortium (IPDGC) members, collaborators, and public resources. As previously described, all data sets underwent quality 
control separately, both on individual-level data and variantlevel data, as implemented using PLINK v1.90b5.3. ${ }^{27,32}$ Briefly, we excluded individual samples with low or excess heterozygosity or discordant sex. We also excluded ancestry outliers following principal component analysis. We required that SNPs have a minimum call rate of $95 \%$, minor allele frequency $(\mathrm{MAF})>5 \%$, and Hardy-Weinberg equilibrium $p$ values $>1 \mathrm{E}-04$. Imputation was performed using the Michigan imputation server and the Haplotype Reference Consortium (r1.1 2016), with Eagle v2.3 phasing available at: imputationserver.sph.umich.edu.

\section{Statistical Analysis}

Our GWAS followed prior published IPDGC analytic pipelines, ${ }^{27,32}$ and an analysis plan was formulated before execution of the study. For each included cohort, the imputed genotyped dosages were analyzed using regression, implemented in RVTESTS. ${ }^{33}$ Logistic regression was used for the dichotomous motor subtype trait (TD vs PIGD), and linear regression was used for the continuous tremor/PIGD score ratio trait. Both models were controlled for age at onset, sex, disease duration, and the first 5 ancestry principal components. Fixed effects meta-analysis combining the summary statistics from the 8 studies was performed using METAL with default parameters. ${ }^{34}$ For the GWAS, we computed Lambda $1000=0.88$ for the dichotomous subtype outcome and Lambda $=0.99$ for the continuous ratio trait. Heterogeneity statistics are included in e-tables, links.lww.com/NXG/A373. As in prior IPDGC analyses, we conservatively filtered the top GWAS results, excluding 6 SNPs with heterogeneity $\mathrm{I}^{2}>60 \%$ and $p<0.05$. For the candidate analysis of PD risk alleles, 71 variants had an imputation quality $>0.8$ in our data set and were therefore included in our analyses. ${ }^{35}$ The significance threshold was set at $p<0.0007$ based on 71 independent tests using the Bonferroni method $(p=0.05 / 71)$; we secondarily considered $p<0.05$ as evidence of a suggestive association. The $71 \mathrm{PD}$ risk variants were also evaluated in combination using a weighted genetic risk score (GRS), implemented in PLINK ${ }^{32,35}$ For ease of interpretation, GRS scores were converted to $\mathrm{Z}$ scores as previously described. ${ }^{36}$ Association with the 2 subtype outcome traits was tested using the formula:

\section{Trait $\sim$ GRS_Zscore + AgeAtOnset + Sex + PC1 - PC5}

Forest plots and association meta $p$-values were calculated using the R package metafor. ${ }^{37}$ For the genome-wide analysis, significance was set at $p<5 \times 10^{-8}$, whereas $p<1 \times 10^{-5}$ was considered suggestive evidence of association. Locus plots were generated using LocusZoom. ${ }^{38}$ Linkage disequilibrium pruning was performed using the module SNPclip, which is part of LDlink application using the default parameters $\left(\mathrm{r}^{2}=\right.$ 0.1 and MAF $=0.01)$ and a genomic window of $500 \mathrm{~kb} .{ }^{39}$ For the lookups of variant associations with essential tremor (ET) susceptibility, significance was set at $p<0.0013$ based on 39 tests. Statistical power was estimated using the Genetic Association Study Power Calculator (csg.sph.umich.edu/abecasis/gas_power_calculator/). We performed 2 sets of calculations considering power to detect association of (1) an established PD risk allele ( $r s 199351$, frequency $=0.6$, risk ratio $=1.11)$ or $(2)$ a novel variant $(r s 10937625$, frequency $=0.12$, risk ratio $=1.25)$. Disease prevalence was set to 0.0041 .

\section{Data Availability}

Summary statistics for the analyses presented in this study will be made available on the IPDGC website (pdgenetics.org/ resources).

\section{Results}

Overall, our study included 3,212 subjects with complete clinical data and genotypes passing all quality control filters (see Methods). Clinical and demographic information along with the frequency of motor subtypes is shown in table 1 . The TD subtype was more common than PIGD, but subtype proportions varied between cohorts (table e-1, links.lww. com/NXG/A373). Consistent with prior reports, ${ }^{14,15,40}$ the proportion of patients with TD was inversely related to average disease duration (correlation coefficient -0.57). Because of individuals with indeterminate subtype classification, 2,829 subjects were available for the GWAS using the dichotomous subtype trait (TD vs PIGD), whereas all 3,212 patients were included in the GWAS for the tremor/PIGD subtype ratio.

We first examined associations for 71 established PD risk variants with PD motor subtypes. Overall, we identified suggestive associations $(p<0.05)$ between risk variants at the GPNMB, SH3GL2, HIP1R, FBRSL1, and RIT2 loci and the subtype trait, but none of these associations remained significant following multiple test correction (table 2 and e-2, links.lww.com/NXG/A379). In 2 of 5 loci (GPNMB and FBRSL1), the PD risk-increasing allele was associated with PIGD subtype. Variants at GPNMB and SH3GL2 also showed

Table 1 Cohort Characteristics

\begin{tabular}{ll}
\hline $\mathbf{N}$ & $\mathbf{N}(\%)$ or mean (SD) \\
\hline Male & 3,212 \\
\hline Age at evaluation (y) & $2,078(64.7)$ \\
\hline Age at onset (y) & $66.0(9.5)$ \\
\hline Disease duration (y) & $61.0(10.6)$ \\
\hline TD subtype & $4.1(4.5)$ \\
\hline PIGD subtype & $1,570(48.9)$ \\
\hline Indeterminant subtype & $1,259(39.2)$ \\
\hline
\end{tabular}

Abbreviations: PIGD = postural instability/gait difficulty; $\mathrm{TD}=$ tremor dominant.

Demographic information and frequency of motor subtypes of the study population combined from all 8 cohorts. 
Table 2 Association of Established PD Risk Variants With PD Motor Subtype

\begin{tabular}{|c|c|c|c|c|c|c|c|c|c|c|}
\hline \multirow[b]{2}{*}{ chr: position } & \multirow[b]{2}{*}{ SNP } & \multirow[b]{2}{*}{ Gene } & \multirow[b]{2}{*}{ Allele $^{a}$} & \multirow[b]{2}{*}{ Frequency } & \multicolumn{3}{|c|}{ Subtype (TD vs PIGD) } & \multicolumn{3}{|c|}{ Subtype ratio } \\
\hline & & & & & Effect & SE & $p$ Value & Effect & SE & $p$ Value \\
\hline 7: 23300049 & rs199351 & GPNMB & $\mathrm{A} / \mathrm{C}$ & 0.61 & 0.16 & 0.06 & 0.011 & -0.05 & 0.02 & 0.033 \\
\hline 9: 17727065 & rs10756907 & $S H 3 G L 2$ & $\mathrm{~A} / \mathbf{G}$ & 0.76 & 0.16 & 0.07 & 0.019 & -0.06 & 0.03 & 0.017 \\
\hline 12: 123326598 & rs10847864 & $H I P 1 R$ & $T / G$ & 0.38 & -0.15 & 0.06 & 0.018 & 0.017 & 0.02 & 0.47 \\
\hline 12:133063768 & rs11610045 & FBRSL1 & $A / G$ & 0.51 & 0.14 & 0.06 & 0.023 & -0.03 & 0.02 & 0.17 \\
\hline 18: 40673380 & rs12456492 & RIT2 & $A / G$ & 0.67 & 0.15 & 0.06 & 0.019 & -0.008 & 0.02 & 0.73 \\
\hline
\end{tabular}

Abbreviations: $\mathrm{PD}=$ Parkinson disease; PIGD = postural instability/gait difficulty; $\mathrm{SE}=$ standard error; $\mathrm{TD}=$ tremor dominant.

a Effect/alternate alleles shown, PD risk allele denoted in boldface.

consistent associations with subtype ratio, but no additional PD risk alleles were associated with this outcome (table e-2, links. lww.com/NXG/A379). We next integrated genotypes across the $71 \mathrm{PD}$ risk alleles to compute a GRS for each subject and examined for association with PD motor subtypes. Indeed, we detected a significant association between the PD GRS and the subtype ratio $(p=0.03$, confidence interval $=-0.07$ to 0.00$)$, although this result appeared to be driven by only 2 of 8 cohorts included in our meta-analysis (PDBP and BCM2, figure 1). The GRS was not associated with the dichotomous subtype trait (figure e-1, links.lww.com/NXG/A373).

We next examined the results of our GWAS to identify novel candidate modifiers of PD motor subtype. Although no variants reached the genome-wide significance threshold, a number of variants showed suggestive associations $\left(p<1 \times 10^{-5}\right)$ with either PD motor subtype or subtype ratio (tables e-3 and e-4, links.lww. com/NXG/A373). The top variant associated with the subtype ratio outcome is $r s 2301857\left(p_{\text {ratio }}=6.6 \times 10^{-7}\right)$, located within an intron of the $S T K 32 B$ gene (figure 2). The minor allele, $r s 2301857^{T}$ (frequency $=0.12$ ) was associated with reduced tremor/PIGD score ratio (effect $=-0.19$ ). Thus, the minor and major alleles for the $r 2301857$ SNP are associated with a polarization toward the PIGD vs TD phenotypes, respectively. In our complementary analysis, the association between $r 2301857$ and PD motor subtype was attenuated $\left(p_{\text {subtype }}=0.044\right)$.

Notably, an association signal at $S T K 32 B$ has been previously reported in a GWAS for ET. ${ }^{41}$ Although the lead variant from that study, $r s 10937625$, is only $290 \mathrm{~kb}$ proximal from the top variant in our analysis, these SNPs do not demonstrate appreciable linkage disequilibrium $\left(\mathrm{R} 2=0.002, \mathrm{D}^{\prime}=0.184\right)$. Based on the Genotype-Tissue Expression project database, ${ }^{42}$ $r s 2301857^{T}$ is associated with increased STK32B expression, but this expression quantitative trait locus was only significant in the testes, salivary gland, and prostate. We performed additional analyses to explore for a possible genetic overlap between ET and PD motor subtype. However, neither the STK $32 B$ variant nor any of the other 5 published ET risk variants ${ }^{41}$ were associated with either of our PD motor subtype traits (table e-5, links.lww.com/NXG/A373). Lastly, to explore for further potential evidence of shared genetic architecture, we reciprocally examined whether any of our top candidate variants $\left(p<1 \times 10^{-5} ; \mathrm{n}=39\right.$ variants $)$ associated with PD motor subtype confers susceptibility for ET, based on lookup of the top results in the largest GWAS completed to date (2807 ET cases/6,441 controls) ${ }^{41,43}$ However, neither $\operatorname{STK}_{22 B^{r 22301857}}(p=0.18)$ nor any other top suggestive results from our PD motor subtype GWAS were significantly associated with ET susceptibility.

\section{Discussion}

Identification and characterization of PD subtypes has received increased attention in recent years, with the goal of predicting progression, stratifying patients based on risk of

Figure 1 PD Genetic Risk Score Associates With Tremor/ Postural Instability/Gait Difficulty Score Ratio

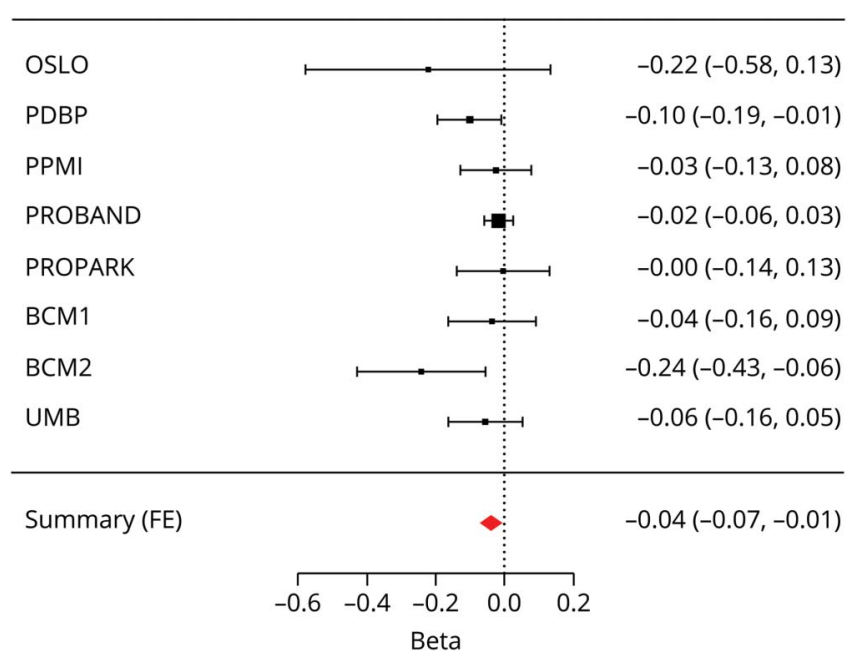

Error bars represent $95 \%$ confidence intervals. The size of the black squares represents the effect size from each cohort. The combined estimate for all cohorts is represented by the red diamond with the width of the diamond representing the $95 \%$ confidence interval bounds. The summary effect $=$ $-0.0389(p=0.0156)$. PD = Parkinson disease. 


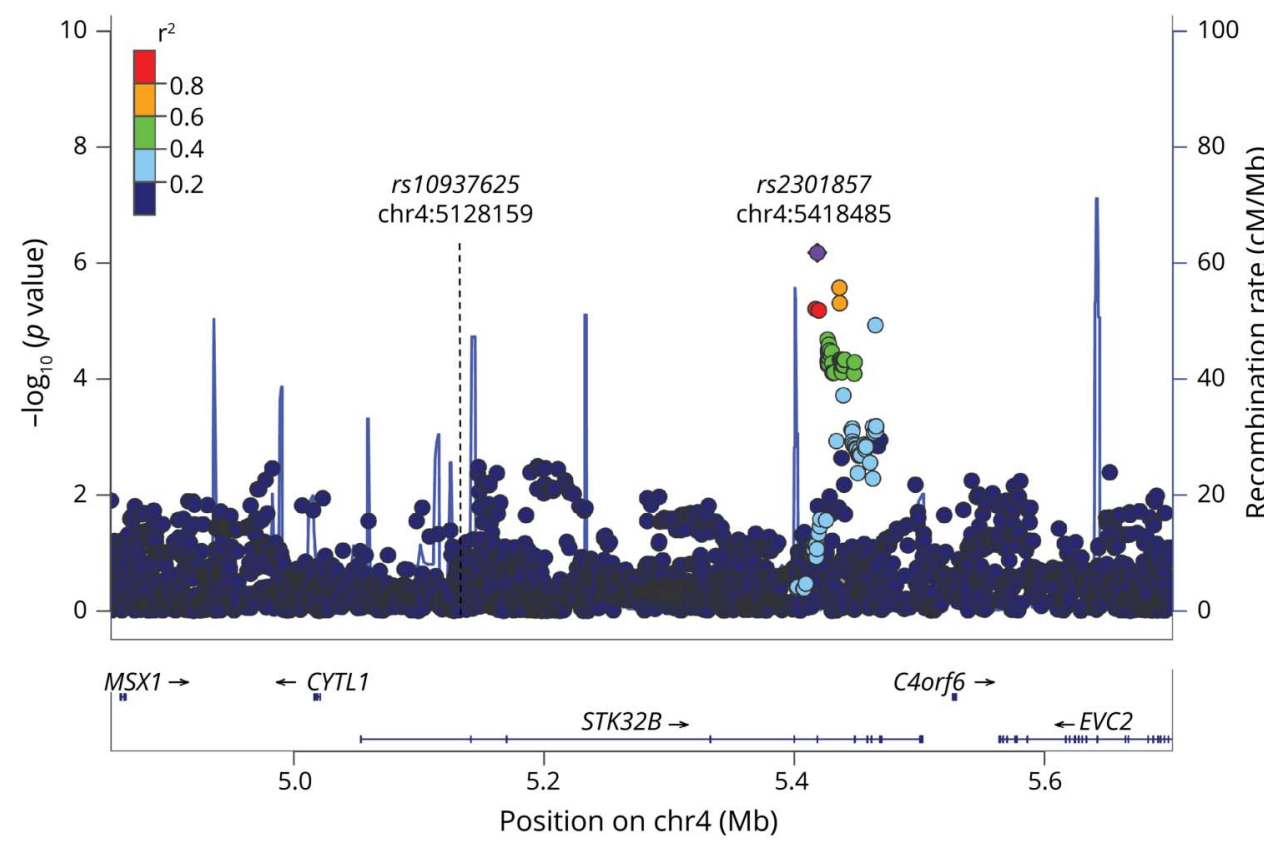

Locus zoom plot highlighting the association signal at the STK32B locus. The top variant associated with PD subtype ratio, rs2301857, is highlighted along with other variants in linkage disequilibrium. Another variant in the same gene, rs10937625 (dashed line), has been reported as significantly associated with essential tremor (ET), but is not associated with PD subtype ratio. The 2 variants appear independent and do not show substantial linkage disequilibrium $\left(R 2=0.002, D^{\prime}=0.184\right) . P D=$ Parkinson disease

nonmotor complications (e.g., dementia), and elucidating mechanisms of disease heterogeneity. ${ }^{7-9,44}$ Recent studies strongly suggest that genetic factors can influence the presence and severity of many varied PD manifestations and therefore likely influence disease subtypes. ${ }^{7}$ We have performed a GWAS for PD motor subtype. Our results highlight some evidence for 5 established PD risk alleles as potential modifiers of motor subtype, and we further found that a PD GRS including 71 risk variants was associated with subtype ratio. One strength of our analysis was consideration of 2 complementary PD motor subtype outcomes. The TD/PIGD score ratio trait offers a continuous outcome and has the advantage of a larger sample size because subjects with indeterminate subtype can be considered. On the other hand, by including subjects with a mixed phenotype, it is also possible that the subtype ratio may dilute power to detect the effects of certain variants. In such cases, the dichotomous subtype outcome permits greater contrast between groups of subjects manifesting the TD or PIGD phenotype. In a prior, candidate-based analysis of 10 PD risk alleles in 810 PD cases, a variant at the SNCA locus ( $r s 356182$ ) was discovered to be associated $(p=0.004, \beta=0.7)$ with a similar TD/PIGD score ratio outcome. ${ }^{23}$ Although we did not replicate that association in our larger sample $(\mathrm{n}=3,212, p=0.18, \beta=0.03)$, this may relate to modest differences in the derivation of the subtype score ratio, and additional replication analyses should be undertaken in the future.

Although no variants reached genome-wide significance in our GWAS, we identify many loci harboring suggestive associations that may be excellent candidates for follow-up and potential replication. The top result of the subtype ratio
GWAS, $r s 2301857$, implicates the STK32B gene as a possible modifier of PD motor phenotypes. This gene has previously been genetically linked to ET. ${ }^{41}$ The potential relationship between ET and PD has long been a topic of discussion in the field of movement disorders. ${ }^{45}$ Although most patients with ET do not develop parkinsonism, at least 1 study has shown that a prior diagnosis of ET may increase the risk of PD up to 4-fold. ${ }^{46,47} \mathrm{~A}$ possible genetic link is further suggested by reports of familial coaggregation of ET and $\mathrm{PD} .{ }^{48}$ In another study, patients with PD having family members with ET were more likely to exhibit the TD subtype of PD. ${ }^{49}$ Importantly, the variant that we discovered in association with PD motor subtype does not show appreciable linkage disequilibrium with the previously reported ET susceptibility signal; therefore, these appear to be independent alleles at the STK32B gene locus. Thus, although intriguing, our results fall short of providing conclusive evidence of a shared genetic architecture of these 2 common movement disorders.

Despite including more than 3,000 subjects, statistical power appeared limiting. In fact, we estimate (see Methods) that nearly 14,000 subjects would be required to achieve $80 \%$ power to detect a significant association for either a candidate PD risk variant (e.g., GPNMB $B^{r s 199351}$ ) or a novel variant modifier of motor subtype (e.g., STK32B ${ }^{r s 2301857}$ ). Based on ongoing efforts, we anticipate that sufficiently large cohorts with detailed clinical phenotyping will likely emerge in the next few years. At the time that this analysis was undertaken, clinical and genetic data were available predominantly from European ancestry subjects. Whereas an ethnically homogenous cohort design may reduce potential population stratification and thereby increase power, this also potentially limits 
generalizability. In the future, it will also be important to study genetic modifiers of PD motor heterogeneity in diverse populations.

Although the TD and PIGD categories are the earliest and mostly widely used subtype classification, ${ }^{8,9}$ there are also several notable limitations. The cutoffs used for differentiating the TD or PIGD subtypes are somewhat arbitrary and without underlying biological or clinical rationale. ${ }^{1}$ In addition, treatment with dopaminergic medication is known to alter the motor UPDRS examination-especially gait scores-which may in turn influence subtype classification. ${ }^{15,50}$ Information on medication status and other factors (e.g., dementia, lifestyle, and environmental exposures) was not universally available for consideration as potential confounders or genetic modifiers in this analysis. Lastly, several recent studies have suggested that PD motor subtypes may shift from TD to PIGD subtype along with disease progression, ${ }^{14-16}$ raising questions about the stability of these phenotypes over time. This relation between disease duration and subtype proportions was recapitulated among the cohorts included in this study (table e-1, links.lww.com/NXG/A373). Such observations suggest that motor subtypes may represent a transient state rather than a static trait. ${ }^{51}$ To control for potential shifts in subtype phenotypes, our analyses were adjusted for both onset age and estimated disease duration. In addition, we speculate that even if PD motor subtypes are dynamic, either completely or in part, they may nevertheless serve as a useful proxy for disease progression, which is likely itself under genetic influence. ${ }^{19,22,24,26}$ In sum, regardless of evolving interpretations for PD subtypes, we argue that analyses of such phenotypes may identify genetic variants that meaningfully modify the PD clinical course, whether motor manifestations, rate of progression, medication response, or some combination. Future genetic analyses of PD subtypes will also benefit from alternative outcome traits that are independent of medication status and disease duration.

\section{Acknowledgment}

The authors thank all the subjects who donated their time and biological samples to be a part of this study. They thank J. Marinus and J.J. Van Hilten for use of the PROPARK cohort data and for feedback on the manuscript. The International Parkinson Disease Genomics Consortium (IPDGC, pdgenetics.org/partners) is supported in part by the Intramural Research Programs of the National Institute of Neurological Disorders and Stroke (NINDS), the National Institute on Aging (NIA), and the National Institute of Environmental Health Sciences both part of the National Institutes of Health, Department of Health and Human Services; project numbers 1ZIA-NS003154, Z01-AG000949-02, and Z01-ES101986. In addition this work was supported by the Department of Defense (award W81XWH-09-2-0128) and The Michael J. Fox Foundation for Parkinsons Research. This work was supported by National Institutes of Health grants R01NS037167, R01CA141668, and P50NS071674, American Parkinson Disease Association (APDA); Barnes Jewish Hospital
Foundation; and Greater St. Louis Chapter of the APDA. The KORA (Cooperative Research in the Region of Augsburg) research platform was started and financed by the Forschungszentrum für Umwelt und Gesundheit, which is funded by the German Federal Ministry of Education, Science, Research, and Technology and by the State of Bavaria. This study was also funded by the German Federal Ministry of Education and Research (BMBF) under the funding code 031A430A, the EU Joint Programme - Neurodegenerative Diseases Research (JPND) project under the aegis of JPND -www.jpnd.euthrough Germany, BMBF, funding code 01ED1406 and iMed the Helmholtz Initiative on Personalized Medicine. This study is funded by the German National Foundation grant (DFG SH599/6-1) (grant to M.S.), Michael J. Fox Foundation, and MSA Coalition, USA (to M.S.). The French GWAS work was supported by the French National Agency of Research (ANR08-MNP-012). This study was also funded by FranceParkinson Association, Fondation de France, the French program Investissements davenir funding (ANR-10-IAIHU06), and a grant from Assistance Publique-Hôpitaux de Paris (PHRC, AOR-08010) for the French clinical data. This study was also sponsored by the Landspitali University Hospital Research Fund (grant to SSv); Icelandic Research Council (grant to SSv); and European Community Framework Programme 7, People Programme, and IAPP on novel genetic and phenotypic markers of Parkinsons disease and Essential Tremor (MarkMD), contract number PIAP-GA-2008- 230596 MarkMD (to $\mathrm{HP}$ and $\mathrm{JHu}$ ). Institutional research funding IUT20-46 was received of the Estonian Ministry of Education and Research (SK). The McGill study was funded by the Michael J. Fox Foundation and the Canadian Consortium on Neurodegeneration in Aging (CCNA). Mayo Clinic is an American Parkinson Disease Association (APDA) Mayo Clinic Information and Referral Center, an APDA Center for Advanced Research and the Mayo Clinic Lewy Body Dementia Association (LBDA) Research Center of Excellence. OAR is supported by the National Institutes of Health (NIH; R01 NS78086; U54 NS100693, U54 NS110435), the US Department of Defense (W81XWH-17-1-0249), The Little Family Foundation, The Mayo Clinic Functional Genomics of LBD Program the Mayo Clinic Center for Individualized Medicine, and the Michael J. Fox Foundation. Z. K. Wszolek is supported by the NIH, Mayo Clinic Center for Regenerative Medicine, The Sol Goldman Charitable Trust, and Donald G. and Jodi P. Heeringa, the Haworth Family Professorship in Neurodegenerative Diseases fund, and by the Albertson Parkinson's Research Foundation. This study used the highperformance computational capabilities of the Biowulf Linux cluster at the National Institutes of Health, Bethesda, MD (biowulf.nih.gov), and DNA panels, samples, and clinical data from the National Institute of Neurological Disorders and Stroke Human Genetics Resource Center DNA and Cell Line Repository. People who contributed samples are acknowledged in descriptions of every panel on the repository website. The authors thank the French Parkinsons Disease Genetics Study Group and the Drug Interaction with genes (DIGPD) study group: Y. Agid, M. Anheim, F. Artaud, A-M. Bonnet, C. 
Bonnet, F. Bourdain, J.-P. Brandel, C. Brefel-Courbon, M. Borg, A. Brice, E. Broussolle, F. Cormier-Dequaire, J.-C. Corvol, P. Damier, B. Debilly, B. Degos, P. Derkinderen, A. Destée, A. Dürr, F. Durif, A. Elbaz, D. Grabli, A. Hartmann, S. Klebe, P. Krack, J. Kraemmer, S. Leder, S. Lesage, R. Levy, E. Lohmann, L. Lacomblez, G. Mangone, L.-L. Mariani, A.-R. Marques, M. Martinez, V. Mesnage, J. Muellner, F. Ory-Magne, F. Pico, V. Planté-Bordeneuve, P. Pollak, O. Rascol, K. Tahiri, F. Tison, C. Tranchant, E. Roze, M. Tir, M. Vérin, F. Viallet, M. Vidailhet, and A. You. The authors also thank the members of the French 3C Consortium: A Alpérovitch, C Berr, C Tzourio, and $\mathrm{P}$ Amouyel for allowing us to use part of the $3 \mathrm{C}$ cohort and D Zelenika for support in generating the genome-wide molecular data. The authors thank P. Tienari (Molecular Neurology Programme, Biomedicum, University of Helsinki), T. Peuralinna (Department of Neurology, Helsinki University Central Hospital), L. Myllykangas (Folkhalsan Institute of Genetics and Department of Pathology, University of Helsinki), and R. Sulkava (Department of Public Health and General Practice Division of Geriatrics, University of Eastern Finland) for the Finnish controls (Vantaa85 + GWAS data). The authors used genome-wide association data generated by the Wellcome Trust Case-Control Consortium 2 (WTCCC2) from UK patients with Parkinsons disease and UK control individuals from the 1958 Birth Cohort and National Blood Service. Genotyping of UK replication cases on ImmunoChip was part of the WTCCC2 project, which was funded by the Wellcome Trust (083948/Z/07/Z). UK population control data were made available through WTCCC1. This study was supported by the Medical Research Council and Wellcome Trust disease centre (grant WT089698/Z/09/Z to NW, JHa, and $\mathrm{ASc}$ ). As with previous IPDGC efforts, this study makes use of data generated by the Wellcome Trust Case-Control Consortium. A full list of the investigators who contributed to the generation of the data is available from wtccc.org.uk. Funding for the project was provided by the Wellcome Trust under award 076113, 085475 and 090355. This study was also supported by Parkinsons UK (grants 8047 and J-0804) and the Medical Research Council (G0700943 and G1100643). Sequencing and genotyping performed in McGill University was supported by grants from the Michael J. Fox Foundation, the Canadian Consortium on Neurodegeneration in Aging (CCNA), the Canada First Research Excellence Fund (CFREF), awarded to McGill University for the Healthy Brains for Healthy Lives (HBHL) program and Parkinsons Society Canada. The authors thank Jeffrey Barrett and Jason Downing (Illumina Inc) for assistance with the design of the ImmunoChip and NeuroX arrays. DNA extraction work that was performed in the United Kingdom was undertaken at University College London Hospitals, University College London, who received a proportion of funding from the Department of Healths National Institute for Health Research Biomedical Research Centres funding. This study was supported in part by the Wellcome Trust/Medical Research Council Joint Call in Neurodegeneration award (WT089698) to the Parkinsons Disease Consortium (UKPDC), whose members are from the UCL Institute of Neurology, University of Sheffield, and the Medical Research Council Protein Phosphorylation Unit at the University of Dundee. The authors thank the Quebec Parkinsons Network (rpq-qpn.org) and its members. This work was supported by the Medical Research Council grant MR/N026004/1. The Braineac project was supported by the MRC through the MRC Sudden Death Brain Bank Grant (MR/G0901254) to J.H. P.A.L. was supported by the MRC (grants MR/N026004/1 and MR/L010933/1) and Michael J. Fox Foundation for Parkinsons Research. M.A. Nalls participation is supported by a consulting contract between Data Tecnica International and the National Institute on Aging, NIH, Bethesda, MD, USA.

\section{Study Funding}

This research was supported in part by the Intramural research Program of the NIH, National Institute on Aging and the Parkinsons UK (Tracking Parkinsons study J-1101, G-1107, H-1703), and the Medical Research Council (G1100643). G.A.R. receives support from a Canadian Institutes of Health Foundation Grant, and C.L. is funded by the Vanier Graduate Scholarship. D.G. receives funding from Parkinsons UK, the UK National Institute for Health Research, and Glasgow University. J.M.S. was supported by the Huffington Foundation, McGee Foundation, Jan and Dan Duncan Neurological Research Institute at Texas Childrens Hospital, and a Career Award for Medical Scientists from the Burroughs Wellcome Fund. Additional International PD Genomics Consortium funding sources are listed in the Acknowledgments.

\section{Disclosure}

I. Alfradique-Dunham, R. Al-Ouran, R. von Coelln, C. Blauwendraat, E. Hill, L. Luo, A. Stillwell, E. Young, A. Kaw, M. Tan, C. Liao, L. Pihlstrom, J. Marinus, J.J. Van Hilten, D. Grosset, L. Shulman, Z. Liu, G. Rouleau, M. Nalls, A. Singleton, and J. Jankovic report no disclosures relevant to the manuscript. Dr. Nalls consults for Illumina Inc, Lysosomal Therapeutics Inc, the Michael J. Fox Foundation, and Vivid Genomics among others. H Morris is employed by UCL and discloses paid consultancy from Biogen, UCB, AbbVie, Denali, Biohaven, and Lundbeck and lecture fees/honoraria from Biogen, UCB, C4X Discovery, GE Healthcare, Wellcome Trust, and the Movement Disorders Society. Dr Morris is a coapplicant on a patent application related to C9ORF72-Method for diagnosing a neurodegenerative disease (PCT/GB2012/052140). Dr. Grossett received honoraria from GE Healthcare, Bial Pharma, and Vectura plc and consultancy fees from The Glasgow Memory Clinic. J. Shulman consults for the Adrienne Helis Malvin \& Diana Helis Henry Medical Research Foundations. Full disclosure form information provided by the authors is available with the full text of this article at Neurology.org/NG.

\section{Publication History}

Received by Neurology: Genetics June 26, 2020. Accepted in final form December 14, 2020. 
Appendix 1 Authors

\begin{tabular}{lll}
\hline Name & Location & Contribution \\
\hline $\begin{array}{l}\text { Isabel } \\
\begin{array}{l}\text { Alfradique- } \\
\text { Dunham, MD }\end{array}\end{array}$ & $\begin{array}{l}\text { Baylor College } \\
\text { of Medicine }\end{array}$ & $\begin{array}{l}\text { Conceptualization, investigation, } \\
\text { data collection, data analysis, data } \\
\text { curation, writing-original draft, } \\
\text { and writing-review and editing }\end{array}$ \\
\hline $\begin{array}{l}\text { Rami Al-Ouran, } \\
\text { PhD }\end{array}$ & $\begin{array}{l}\text { Baylor College } \\
\text { of Medicine }\end{array}$ & $\begin{array}{l}\text { Conceptualization, investigation, } \\
\text { data analysis, data curation, } \\
\text { methodology, writing-original } \\
\text { draft, and writing-review and } \\
\text { editing }\end{array}$
\end{tabular}

Rainer von University of

Conceptualization, investigation,

Coelln, MD Maryland data collection, data curation, writing-original draft, and writing-review and editing

\begin{tabular}{|c|c|c|}
\hline $\begin{array}{l}\text { Cornelis } \\
\text { Blauwendraat, } \\
\text { PhD }\end{array}$ & $\begin{array}{l}\text { National } \\
\text { Institutes of } \\
\text { Health }\end{array}$ & $\begin{array}{l}\text { Conceptualization, investigation, } \\
\text { data generation, data analysis, } \\
\text { data curation, and writing-review } \\
\text { and editing }\end{array}$ \\
\hline Emily Hill, MD & $\begin{array}{l}\text { Baylor College } \\
\text { of Medicine }\end{array}$ & $\begin{array}{l}\text { Data analysis and writing-original } \\
\text { draft }\end{array}$ \\
\hline $\begin{array}{l}\text { Lan Luo, MD, } \\
\text { MS }\end{array}$ & $\begin{array}{l}\text { Baylor College } \\
\text { of Medicine }\end{array}$ & $\begin{array}{l}\text { Data analysis, data collection, data } \\
\text { curation, and writing-review and } \\
\text { editing }\end{array}$ \\
\hline $\begin{array}{l}\text { Amanda } \\
\text { Stillwell, BA }\end{array}$ & $\begin{array}{l}\text { Baylor College } \\
\text { of Medicine }\end{array}$ & $\begin{array}{l}\text { Data collection, data curation, and } \\
\text { writing-review and editing }\end{array}$ \\
\hline $\begin{array}{l}\text { Emily Young, } \\
\text { MD }\end{array}$ & $\begin{array}{l}\text { Baylor College } \\
\text { of Medicine }\end{array}$ & $\begin{array}{l}\text { Data collection and } \\
\text { writing-review and editing }\end{array}$ \\
\hline Anita Kaw, BA & $\begin{array}{l}\text { Baylor College } \\
\text { of medicine }\end{array}$ & $\begin{array}{l}\text { Data collection and } \\
\text { writing-review and editing }\end{array}$ \\
\hline $\begin{array}{l}\text { Manuela Tan, } \\
\text { BA }\end{array}$ & $\begin{array}{l}\text { University } \\
\text { College London }\end{array}$ & $\begin{array}{l}\text { Conceptualization, data curation, } \\
\text { and writing-review and editing }\end{array}$ \\
\hline $\begin{array}{l}\text { Calwing Liao, } \\
\text { BA }\end{array}$ & $\begin{array}{l}\text { McGill } \\
\text { University }\end{array}$ & $\begin{array}{l}\text { Data analysis and writing-review } \\
\text { and editing }\end{array}$ \\
\hline $\begin{array}{l}\text { Dena G. } \\
\text { Hernandez, } \\
\text { PhD }\end{array}$ & $\begin{array}{l}\text { National } \\
\text { Institutes of } \\
\text { Health }\end{array}$ & $\begin{array}{l}\text { Data generation, data curation, } \\
\text { data analysis, and writing-review } \\
\text { and editing }\end{array}$ \\
\hline $\begin{array}{l}\text { Lasse } \\
\text { Pihlstrom, MD, } \\
\text { PhD }\end{array}$ & $\begin{array}{l}\text { Oslo University } \\
\text { Hospital }\end{array}$ & $\begin{array}{l}\text { Data collection, data curation, and } \\
\text { writing-review and editing }\end{array}$ \\
\hline $\begin{array}{l}\text { Donald } \\
\text { Grosset, MD }\end{array}$ & $\begin{array}{l}\text { Queen Elizabeth } \\
\text { University } \\
\text { Hospital }\end{array}$ & $\begin{array}{l}\text { Data collection, data curation, } \\
\text { writing-review and editing, and } \\
\text { resources }\end{array}$ \\
\hline $\begin{array}{l}\text { Lisa M. } \\
\text { Shulman, MD }\end{array}$ & $\begin{array}{l}\text { University of } \\
\text { Maryland }\end{array}$ & $\begin{array}{l}\text { Conceptualization, data collection, } \\
\text { writing-review and editing, } \\
\text { resources, and supervision }\end{array}$ \\
\hline $\begin{array}{l}\text { Zhandong Liu, } \\
\text { PhD }\end{array}$ & $\begin{array}{l}\text { Baylor College } \\
\text { of Medicine }\end{array}$ & $\begin{array}{l}\text { Conceptualization, } \\
\text { writing-review and editing, } \\
\text { resources, and supervision }\end{array}$ \\
\hline $\begin{array}{l}\text { Guy A. } \\
\text { Rouleau, MD, } \\
\text { PhD }\end{array}$ & $\begin{array}{l}\text { McGill } \\
\text { University }\end{array}$ & $\begin{array}{l}\text { Data curation, writing-review and } \\
\text { editing, supervision, and } \\
\text { resources }\end{array}$ \\
\hline $\begin{array}{l}\text { Mike A. Nalls, } \\
\text { PhD }\end{array}$ & $\begin{array}{l}\text { Data Technica } \\
\text { International }\end{array}$ & $\begin{array}{l}\text { Conceptualization, data curation, } \\
\text { methodology, writing-review and } \\
\text { editing, and supervision }\end{array}$ \\
\hline $\begin{array}{l}\text { Andrew B. } \\
\text { Singleton, PhD }\end{array}$ & $\begin{array}{l}\text { National } \\
\text { Institutes of } \\
\text { Health }\end{array}$ & $\begin{array}{l}\text { Data generation, data curation, } \\
\text { writing-review and editing, } \\
\text { resources, and supervision }\end{array}$ \\
\hline
\end{tabular}

Appendix 1 (continued)

\begin{tabular}{lll}
\hline Name & Location & Contribution \\
\hline $\begin{array}{l}\text { Huw Morris, } \\
\text { MD }\end{array}$ & $\begin{array}{l}\text { University } \\
\text { College London }\end{array}$ & $\begin{array}{l}\text { Conceptualization, data collection, } \\
\text { writing-review and editing, } \\
\text { resources, supervision }\end{array}$ \\
\hline $\begin{array}{l}\text { Joseph } \\
\text { Jankovic, MD }\end{array}$ & $\begin{array}{l}\text { Baylor College } \\
\text { of Medicine }\end{array}$ & $\begin{array}{l}\text { Conceptualization, data collection, } \\
\text { writing-review and editing, } \\
\text { resources, and supervision }\end{array}$ \\
$\begin{array}{l}\text { Joshua M. } \\
\text { Shulman, MD, } \\
\text { PhD }\end{array}$ & $\begin{array}{l}\text { Baylor College } \\
\text { of Medicine }\end{array}$ & $\begin{array}{l}\text { Conceptualization, } \\
\text { writing-original draft, } \\
\text { writing-review and editing, } \\
\text { resources, and supervision }\end{array}$ \\
\hline
\end{tabular}

\section{Appendix 2 Coinvestigators}

Coinvestigators are listed at links.lww.com/NXG/A374.

\section{References}

1. Jankovic J, McDermott M, Carter J, et al. Variable expression of Parkinson's disease: a base-line analysis of the DATATOP cohort. Parkinson Study Group. Neurology 1990;40:1529-1534.

2. Stebbins GT, Goetz CG, Burn DJ, Jankovic J, Khoo TK, Tilley BC, How to identify tremor dominant and postural instability/gait difficulty groups with the movement disorder society unified Parkinson's disease rating scale: comparison with the unified Parkinson's disease rating scale. Mov Disord 2013;28:668-670.

3. Schiess MC, Zheng H, Soukup VM, Bonnen JG, Nauta HJ. Parkinson's disease subtypes: clinical classification and ventricular cerebrospinal fluid analysis. Parkinsonism Relat Disord 2000;6:69-76.

4. Kang GA, Bronstein JM, Masterman DL, Redelings M, Crum JA, Ritz B. Clinical characteristics in early Parkinson's disease in a central California population-based study. Mov Disord 2005;20:1133-1142).

5. van Rooden SM, Colas F, Martínez-Martín P, et al. Clinical subtypes of Parkinson's disease. Mov Disord 2011;26:51-58.

6. Fereshtehnejad SM, Zeighami Y, Dagher A, Postuma RB. Clinical criteria for subtyping Parkinson's disease: biomarkers and longitudinal progression. Brain 2017;140: 1959-1976.

7. von Coelln R, Shulman LM. Clinical subtypes and genetic heterogeneity: of lumping and splitting in Parkinson disease. Curr Opin Neurol 2016;29:727-734.

8. Marras C, Lang A. Parkinson's disease subtypes: lost in translation? J Neurol Neurosurg Psychiatry 2013;84:409-415.

9. Thenganatt MA, Jankovic J. Parkinson disease subtypes. JAMA Neurol 2014;71: 499-504.

10. Jankovic J, Kapadia AS. Functional decline in Parkinson disease. Arch Neurol 2001; 58:1611-1615.

11. Alves G, Larsen JP, Emre M, Wentzel-Larsen T, Aarsland D. Changes in motor subtype and risk for incident dementia in Parkinson's disease. Mov Disord 2006;21: 1123-1130.

12. Paulus W, Jellinger K. The neuropathologic basis of different clinical subgroups of Parkinson's disease. J Neuropathol Exp Neurol 1991;50:743-755.

13. Selikhova M, Williams DR, Kempster PA, Holton JL, Revesz T, Lees AJ A clinicopathological study of subtypes in Parkinson's disease. Brain 2009;132:2947-2957.

14. Eisinger RS, Hess CW, Martinez-Ramirez D, et al. Motor subtype changes in early Parkinson's disease. Parkinsonism Relat Disord 2017;43:67-72.

15. Luo L, Andrews $\mathrm{H}$, Alcalay RN, et al. Motor phenotype classification in moderate to advanced PD in BioFIND study. Parkinsonism Relat Disord 2019;65:178-183.

16. Simuni T, Caspell-Garcia C, Coffey $\mathrm{C}$, et al. How stable are Parkinson's disease subtypes in de novo patients: analysis of the PPMI cohort?. Parkinsonism Relat Disord 2016;28:62-67.

17. Hernandez DG, Reed X, Singleton AB. Genetics in Parkinson disease: mendelian versus non-Mendelian inheritance. J Neurochem 2016;139(suppl 1):59-74.

18. Healy DG, Falchi M, O'Sullivan SS, et al. Phenotype, genotype, and worldwide genetic penetrance of LRRK2-associated Parkinson's disease: a case-control study. Lancet Neurol 2008;7:583-590.

19. Davis MY, Johnson CO, Leverenz JB, et al. Association of GBA mutations and the E326K polymorphism with motor and cognitive progression in Parkinson disease. JAMA Neurol 2016;73:1217-1224.

20. Goris A, Williams-Gray CH, Clark GR, et al. Tau and alpha-synuclein in susceptibility to, and dementia in, Parkinson's disease. Ann Neurol 2007;62:145-153. 
21. Brockmann K, Schulte C, Hauser AK, et al. SNCA: major genetic modifier of age at onset of Parkinson's disease. Mov Disord 2013;28:1217-1221.

22. Davis AA, Andruska KM, Benitez BA, Racette BA, Perlmutter JS, Cruchaga C. Variants in GBA, SNCA, and MAPT influence Parkinson disease risk, age at onset, and progression. Neurobiol Aging 2016;37:209 e201-e7 e207.

23. Cooper CA, Jain N, Gallagher MD, et al. Common variant rs356182 near SNCA defines a Parkinson's disease endophenotype. Ann Clin Transl Neurol 2017;4:15-25.

24. Latourelle JC, Beste MT, Hadzi TC, et al. Large-scale identification of clinical and genetic predictors of motor progression in patients with newly diagnosed Parkinson's disease: a longitudinal cohort study and validation. Lancet Neurol 2017;16:908-916.

25. Bjornara KA, Pihlstrom L, Dietrichs E, Toft M. Risk variants of the alpha-synuclein locus and REM sleep behavior disorder in Parkinson's disease: a genetic association study. BMC Neurol 2018;18:20.

26. Iwaki H, Blauwendraat C, Leonard HL, et al. Genetic risk of Parkinson disease and progression: an analysis of 13 longitudinal cohorts. Neurol Genet 2019;5:e348.

27. Blauwendraat C, Heilbron K, Vallerga CL, et al. Parkinson's disease age at onse genome-wide association study: defining heritability, genetic loci, and alpha-synuclein mechanisms. Mov Disord 2019;34:866-875.

28. Iwaki $\mathrm{H}$, Blauwendraat $\mathrm{C}$, Leonard $\mathrm{HL}$, et al. Genomewide association study of Parkinson's disease clinical biomarkers in 12 longitudinal patients' cohorts. Mov Disord 2019;34:1839-1850.

29. Alcalay RN, Mejia-Santana H, Tang MX, et al. Motor phenotype of LRRK2 G2019S carriers in early-onset Parkinson disease. Arch Neurol 2009;66:1517-1522.

30. Fahn S, Elton RL. UPDRS program members Parkinson's Disease Rating Scale. In: Fahn S, Marsden CD, Goldstein M, Calne CB, editors. Recent Developments in Parkinson's Disease. Vol. 2. Florham Park, NJ: Macmillan Healthcare Information; 1987:153-163.

31. Goetz CG, Tilley BC, Shaftman SR, et al. Movement disorder society-sponsored revision of the unified Parkinson's disease rating scale (MDS-UPDRS): scale presentation and clinimetric testing results. Mov Disord 2008;23:2129-2170.

32. Purcell S, Neale B, Todd-Brown K, et al. PLINK: a tool set for whole-genome association and population-based linkage analyses. Am J Hum Genet 2007;81:559-575.

33. Zhan X, Hu Y, Li B, Abecasis GR, Liu DJ. RVTESTS: an efficient and comprehensive tool for rare variant association analysis using sequence data. Bioinformatics 2016;32:1423-1426.

34. Willer CJ, Li Y, Abecasis GR. METAL: fast and efficient meta-analysis of genomewide association scans. Bioinformatics 2010;26:2190-2191.

35. Nalls MA, Blauwendraat C, Vallerga CL, et al. Identification of novel risk loci, causal insights, and heritable risk for Parkinson's disease: a meta-analysis of genome-wide association studies. Lancet Neurol 2019;18:1091-1102.
36. Nalls MA, Escott-Price V, Williams NM, et al. Genetic risk and age in Parkinson's disease: continuum not stratum. Mov Disord 2015;30:850-854.

37. Viechtbauer W. Conducting meta-analyses in $\mathrm{R}$ with the metafor package. 2010 36:48.

38. Pruim RJ, Welch RP, Sanna S, et al. LocusZoom: regional visualization of genomewide association scan results. Bioinformatics 2010;26:2336-2337.

39. Machiela MJ, Chanock SJ. LDlink. a web-based application for exploring populationspecific haplotype structure and linking correlated alleles of possible functional variants. Bioinformatics 2015;31:3555-3557.

40. van der Heeden JF, Marinus J, Martinez-Martin P, Rodriguez-Blazquez C, Geraedts VJ, van Hilten JJ. Postural instability and gait are associated with severity and prognosis of Parkinson disease. Neurology 2016;86:2243-2250.

41. Müller SH, Girard SL, Hopfner F, et al. Genome-wide association study in essential tremor identifies three new loci. Brain 2016;139:3163-3169.

42. Consortium GT. The GTEx Consortium atlas of genetic regulatory effects across human tissues. Science 2020;369:1318-1330.

43. Liao C, Sarayloo F, Rochefort D, et al. Multiomics analyses identify genes and pathways relevant to essential tremor. Mov Disord 2020;35:1153-1162.

44. Marras C. Subtypes of Parkinson's disease: state of the field and future directions. Curr Opin Neurol 2015;28:382-386.

45. Tarakad A, Jankovic J. Essential tremor and Parkinson's disease: exploring the relationship. Tremor Other Hyperkinet Mov (N Y) 2018;8:589.

46. Adler CH, Shill HA, Beach TG. Essential tremor and Parkinson's disease: lack of a link. Mov Disord 2011;26:372-377.

47. Benito-Leon J, Louis ED, Bermejo-Pareja F. Neurological Disorders in Central Spain Study, G. Risk of incident Parkinson's disease and parkinsonism in essential tremor: a population based study. J Neurol Neurosurg Psychiatry 2009; 80:423-425.

48. Louis ED, Clark L, Ottman R. Familial aggregation and co-aggregation of essential tremor and Parkinson's disease. Neuroepidemiology 2016;46:31-36.

49. Hedera P, Fang JY, Phibbs F, Cooper MK, Charles PD, Davis TL. Positive family history of essential tremor influences the motor phenotype of Parkinson's disease. Mov Disord 2009;24:2285-2288.

50. Vu TC, Nutt JG, Holford NH. Progression of motor and nonmotor features of Parkinson's disease and their response to treatment. Br J Clin Pharmacol 2012;74: 267-283.

51. Nutt JG. Motor subtype in Parkinson's disease: different disorders or different stages of disease? Mov Disord 2016;31:957-961. 


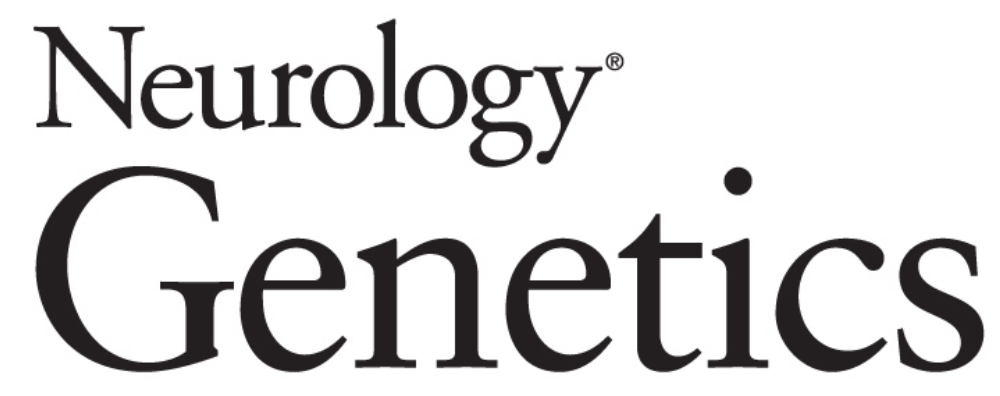

\section{Genome-Wide Association Study Meta-Analysis for Parkinson Disease Motor Subtypes Isabel Alfradique-Dunham, Rami Al-Ouran, Rainer von Coelln, et al. Neurol Genet 2021;7; \\ DOI 10.1212/NXG.0000000000000557}

This information is current as of January 28,2021

\author{
Updated Information \& \\ Services \\ References \\ Citations \\ Subspecialty Collections
}

Permissions \& Licensing

Reprints including high resolution figures, can be found at: http://ng.neurology.org/content/7/2/e557.full.html

This article cites 50 articles, 4 of which you can access for free at: http://ng.neurology.org/content/7/2/e557.full.html\#\#ref-list-1

This article has been cited by 3 HighWire-hosted articles: http://ng.neurology.org/content/7/2/e557.full.html\#\#otherarticles

This article, along with others on similar topics, appears in the following collection(s):

Association studies in genetics

http://ng.neurology.org//cgi/collection/association_studies_in_genetics Parkinson's disease/Parkinsonism http://ng.neurology.org//cgi/collection/parkinsons_disease_parkinsonis $\mathrm{m}$

\section{Tremor}

http://ng.neurology.org//cgi/collection/tremor

Information about reproducing this article in parts (figures,tables) or in its entirety can be found online at:

http://ng.neurology.org/misc/about.xhtml\#permissions

Information about ordering reprints can be found online: http://ng.neurology.org/misc/addir.xhtml\#reprintsus

Neurol Genet is an official journal of the American Academy of Neurology. Published since April 2015, it is an open-access, online-only, continuous publication journal. Copyright Copyright $\odot 2021$ The Author(s). Published by Wolters Kluwer Health, Inc. on behalf of the American Academy of Neurology.. All rights reserved. Online ISSN: 2376-7839.

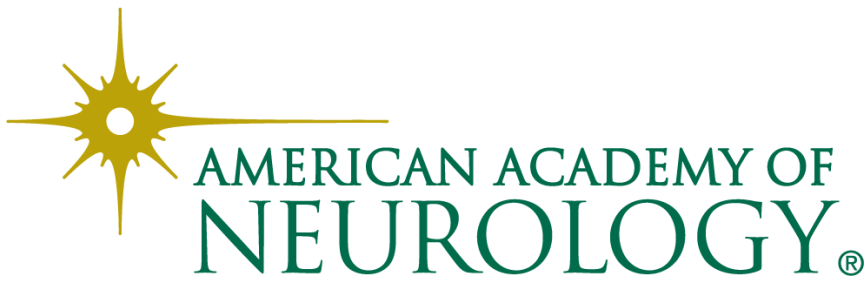

